\title{
Improving the Accuracy of Execution Data of ERP Systems: A Case Study in the Zongxin Telecom Corporation
}

\author{
F. Wu ${ }^{1}$, H. Z. $\mathrm{Li}^{1}, \mathrm{~L} \mathrm{~K} \mathrm{Chu}{ }^{2}$, D. Sculli ${ }^{2}$, and Y. Wu ${ }^{1}$ \\ 1 School of Management, Xi'an Jiaotong University, \\ Xianning Road, Xi'an, PRC. \\ \{fengwu, hzli, ywu\}@mail.xjtu.edu.cn. \\ 2 Department of Industrial and Manufacturing \\ System Engineering, The University of Hong Kong, \\ Pokfulam Road, Hong Kong SAR, China \\ \{lkchu,hreidsc\}@hkucc.hku.hk
}

\begin{abstract}
The poor accuracy of the execution data (AoD) is often seen as a common symptom of unsuccessful enterprise resources planning (ERP) implementation. Finding ways to achieve high AoD is therefore an important and pressing issue for ERP practitioners. This paper describes an AoD improvement project in Zongxin Corporation (China). The approach taken in this project has been to better define AoD and to measure it with the use of five indices including data coincidence, completeness, timeliness, reliability and logical consistency. Five influencing factors of AoD have been identified by examining the current AoD problems of the ERP system implemented in Zongxin Corporation. They include management commitment to and policy on the management of enterprise information, effectiveness of training, the competence of the ERP solution providers, the reliability of the system, and the duration of concurrent running of new and legacy systems. These factors are related to the AoD indices through the development of a structural model, and the cause-and-effect relationships for improving AoD in ERP implementation are established. A relationship matrix between the influencing factors and the AoD indices is established for use in AoD control. The five factors are further explored as controllable and uncontrollable factors in improving AoD. Based on these models, process improvements for AoD are carried out, key control points are identified, and best practices are introduced and reinforced. This paper will also elaborate on the issues relating to ERP training, system reliability and transition
\end{abstract}

Please use the following format when citing this chapter:

Wu, F., Li, H., Z., Chu, L., K., Sculli, D., Wu, Y., 2006, in International Federation for Information Processing, Volume 205, Rescarch and Practical Issues of Enterprise Information Systems, cds. Tjoa, A.M., Xu, L., Chaudhry, S., (Boston:Springer), pp.325-339. 
period, with both new and legacy systems in operations. Ways to improve the effectiveness and to reduce vulnerability will also be discussed.

\section{Introduction}

The successful implementation of an ERP system should lead to considerable benefits for firms entering the e-business field. Unfortunately, a very high failure rate of ERP system implementation (ESI) has deterred potential users from using this important e-business tool. There are several reasons for the frequent failures of ESI; low accuracy of the execution data (AoD) is considered as one of the most common reason. Many examples of failed ESI due to poor AoD can be found, with many firms experiencing considerable frustration during their ESI, and having no other choice but to abort their ERP systems. Therefore, resolving the problem of low AoD seems to be of fundamental importance during the early stage of an ESI.

This study is based on an ESI case in the Zongxin Corporation (ZXC), a major manufacturer of telecom equipment in China. They considered implementing an advanced ERP system to order to enhance its supply chain capabilities. During the planning stage of its ESI project, the company spent considerable resources examining alternative ERP solutions from various vendors. However, unsatisfactory AoD during the project go-live stage presented major problems and critical issues for ZXC. To resolve such critical issues, a solution for enhancing AoD was developed by the authors and will be described in the sections that follow.

\section{Review of Literature}

Researchers in the field of ESI seem to have paid comparatively little attention to AoD when compared to the other factors that lead to effective ESI. Most authors have focused on the indirect factors such as a change of business processes [1,2], top supervisor support [3-5], training [6,7] and cultural factors [8,9]. On the other hand, AoD, which is critical for successful ESI, has not been adequately addressed, with only a small amount of published literature addressing the role of data accuracy in information systems. An example is Stephen [10], who analyzed the tradeoff between data accuracy and the performance of databases. He defined data accuracy as the relevant error between memory data value and true value. Robertson [11] developed an automated data collection model for simulation and the improved the methodologies and mechanisms of selection of potential key data sources. Thomas and Yang [12] proposed a semi-structure constraint-based wrapper specification and verification for enhancing data accuracy in cooperative information systems. While these contributions deal with the data accuracy of database from various perspectives 
in different fields, it is apparent that they lack a systematic approach to achieving data accuracy in ESI.

\section{ERP in the Zongxin Corporation and the low accuracy of AoD}

\subsection{Outline of the Zongxin Corporation}

ZXC is a leading Chinese manufacturer of telecom equipment. It sells three series of products including wireless equipment, networking facilities, and consumer products such as mobile phones. ZXC also provides various solutions and high quality services for users located in many parts of the world. The company is now in the process of expanding its international telecom operational business (e.g. system equipment of mobile phone, personal hand-phone system (PHS), WLAN and BWA). In the mobile communications area, $\mathrm{ZXC}$ has complete production systems for CDMA, and GSM from $2 \mathrm{G}, 2.5 \mathrm{G}$ and $3 \mathrm{G}$ products.

\subsection{ERP Systems Implementation in ZXC}

In the early of 2000's and in response to the then increasing competitive environment worldwide, ZXC decided to adopt an ERP solution to integrate its production, market, purchasing and financial management operations. And so provide an information platform on which to build a unified database and data sources to support the group's business across several countries and regions. The whole business processes and information management ranges right through from order receipts to sales services.

The characteristics of ZXC's business processes were analyzed and investigated and the capabilities of ERP vendors and consultants were thoroughly studied. The Oracle Application ERP and Henkel Technologies were selected as the vendor and the consulting company respectively. Based on the guidelines for ERP implementation and the conclusions reached by both of the project implementation team and consultants, 6 months would be required before the system could go live.

After the system was up and running, various implementation faults appeared which aggravated as time went on. These faults can be divided into the following four general categories:

(1) Accounting faults: All accounting data came from records of past activities. However, in practice, such data was only "re-recorded", instead of being captured at the time when the business transactions took place. As a result, errors propagated and proliferated from one department and to all involved in those transactions. For example, if an invoice was generated in the finance department and if the shipment 
data had not been recorded in the database, the submission of the invoice could not be made because the related shipment records for the new process were missing.

(2) Faults arising from incorrectly using ERP modules: For example, in using the sales order modules, sales staff (usually with self-interest) did not follow the rule of submitting all customer information to the ERP project team. The customer's information, therefore, was not recorded in the database and sales orders could not be issued in the correct way.

(3) Faults due to erroneous data: Financial processes were usually arranged at the end of a series of transactions. Normally, errors arising in prior processes will not be allowed to pass through the financial process. However, if an error was uncovered at the financial process, rectifying such erroneous data at such a late stage would be out of the question. To effectively rectify the problem, the only approach was feedback from earlier processes. This in turn would significantly delay the overall time for completing the process and at the same time a large amount of junk data was generated.

(4) Operational faults: Many operational problems were identified in various departments. Some could be attributed to ignorance of the important business processes, while a mixture of other problems were due to the heterogeneous configuration of software solutions and data.

\subsection{Accuracy of AoD in ZXC}

The most acute among the numerous problems in the implementation of ERP at ZXC were mainly as a result of low AoD and executive data. Although two months had passed since implementation, the executive data extracted from the system generally exhibited low quality as follows:

- Contract data error

Out of a total of 120 purchase orders generated within one month were examined, only $21(17 \%)$ were recorded in the system. As the remaining purchasing orders were not created and issued on time, the raw materials required for them were unable to arrive on time and be received by the warehouse. Consequently, it was not possible to release raw material to production due to missing related records in the raw material warehouse; and consequently no finished products could be received by warehouse, and finally no finished products could be sold.

- Ordering error

There were 926 basic sales orders throughout the year. However, only 734 (79\%) of them were recorded in the system. There were 231 confirmed sales orders in the month under investigation, but only 67 of them were recorded. Such incomplete sales information resulted in a host of related problems such as: money paid for returned goods could not be correctly refunded customers; although the finished goods had been received by the warehouse, the accounting system's inability to record this transaction on time affected production; and low accuracy of sales orders also resulted in the system's inability to issue invoices after the goods had been delivered. 
- Inaccurate production and cost information

In order to investigate the AoD of ESI, the discrepancies between data recorded in ERP and data obtained from actual production system were compared, see Table 1. Information relating to the tasks and costs of production task was explored. Production tasks could be divided into two categories according to whether their production costs can be derived from standard cost data used by ZXC or required special consideration. Moreover, since operators did not perform tasks according to ERP specification, cost errors for standard finished products were created (Table 1) and errors in production cost would inevitably lead to the errors in sales costs.

Table. 1 Error Ratio of Production Task and Production Cost

\begin{tabular}{|c|c|c|c|c|}
\hline Item & Index & $\begin{array}{l}\text { Standard } \\
\text { task }\end{array}$ & $\begin{array}{l}\text { Non-standard } \\
\text { task }\end{array}$ & $\begin{array}{l}\text { Total } \\
\text { task }\end{array}$ \\
\hline \multirow{3}{*}{$\begin{array}{l}\text { Production } \\
\text { task }\end{array}$} & Record of task in ERP system & 86 & 44 & 130 \\
\hline & $\begin{array}{l}\text { Actual task in production } \\
\text { system }\end{array}$ & 269 & 143 & 412 \\
\hline & Error ratio & $32 \%$ & $30 \%$ & $32 \%$ \\
\hline \multirow{3}{*}{$\begin{array}{l}\text { Production } \\
\text { cost }\end{array}$} & $\begin{array}{l}\text { Amount of products in ERP } \\
\text { system at correct cost }\end{array}$ & 124 & 52 & 176 \\
\hline & Amount of actual products & 269 & 143 & 412 \\
\hline & Error ratio & $46 \%$ & $36 \%$ & $42 \%$ \\
\hline
\end{tabular}

- System bugs

There were 102 sales orders recorded in the system during the month, which included 35 "virtual orders". Such virtual orders were generated to resolve bugs in the system. For example, if a virtual order was generated in a designated warehouse, errors in product delivery should appear. The occurrence of such an error would stop further operations, which in turn invoked quick fixes such as a virtual shipment or a virtual return to deal with the error. Such errors and related actions further aggravated $\mathrm{AoD}$ in related activities.

- Invoice errors

183 invoices in the module of receivable management in the month were examined. Of these, 54 errors relating to taxation were found in invoices. Moreover, incorrect data in invoices were due to the numerous human errors. To deal with these erroneous invoices, a series of hedge invoices were generated and this measure resulted in the inflation of unnecessary information. 
- Inventory data errors

At the end of the month, there were over 200 codes of finished products in inventory. Unfortunately, every inventory code was found to be different from the one recorded in the system. The ratio of accurate data of inventory-checking was almost zero.

- Delaying of production task record

There were 412 tasks completed and received in warehouse during the month, and 78 of them (on average) were duly recorded in the system everyday. The ratio of timely updating of accounting records after task completion and warehouse receipt was $19 \%$,

- BOM errors

5 outdated BOM were uncovered in the system because the updated versions had not been properly maintained. This inevitably led to successive errors in production, material release, and cost management.

The primary objective of ESI is to create an effective database in which accurate information of purchasing, production and sales activities becomes available online. This aspect is the crucial to achieve clear visibility in the extended enterprise and to synchronize the enterprise-wide transactions. Unfortunately, this object can easily and often be defeated by data that are flawed with errors, delay in data input, etc. $A \circ D$ is susceptible in many ways, some of which are inadvertent and comes as "natural" because of the user's ability to come to terms of a new way of working. Sometimes "errors" are a result of a need to explore (play) the system in order to correct other errors. The large volume of junk data entered into or generated by the system are not easy to identify and removed. Worse still, such cleansing is not always possible because of the enormity of the task involved in detecting the numerous production tasks, orders, and manual replenishment and reverse invoices, and to systematically delete them.

The low AoD in ZXC prevented top supervisors from getting the necessary data from the system for making correct and timely decisions, resulting in a negative impact on production.

\section{Analysis of the Factors and the Relationship Model for AoD}

\subsection{The Indices of Accuracy Data}

AoD can be generally defined as the ratio of correct data to the total recorded data in an ERP system over a defined period of time. Our investigation of the problem suggests that ways to enhance AoD rest on achieving the data properties of coincidence, completeness, timeliness, reliability and logical consistency, which can be defined as follows:

- Coincidence: the data recorded in system is the same as the actual data. 
- Completeness: the data recorded in system is complete and there should not be any missing or redundant data.

- Timeliness: real-time recording of any data required in processes.

- Reliability: ensuring system is safe and reliable and all the required maintenance-related functions are performed punctually.

- Logical consistency: that there are no logical errors in data used by the system.

Five indices were developed based on the above five properties.

\subsection{Critical factors for AoD}

Based on the analysis of the AOD phenomena in the ZXC case, several influencing factors for AoD in ESI have been proposed including management commitment and policy, system reliability, competence of ERP solution providers, training effectiveness, and duration of concurrent running of new and legacy systems. These factors could be divided into two groups including the system factor and human factor. The structure of model was shown in Fig. 1.

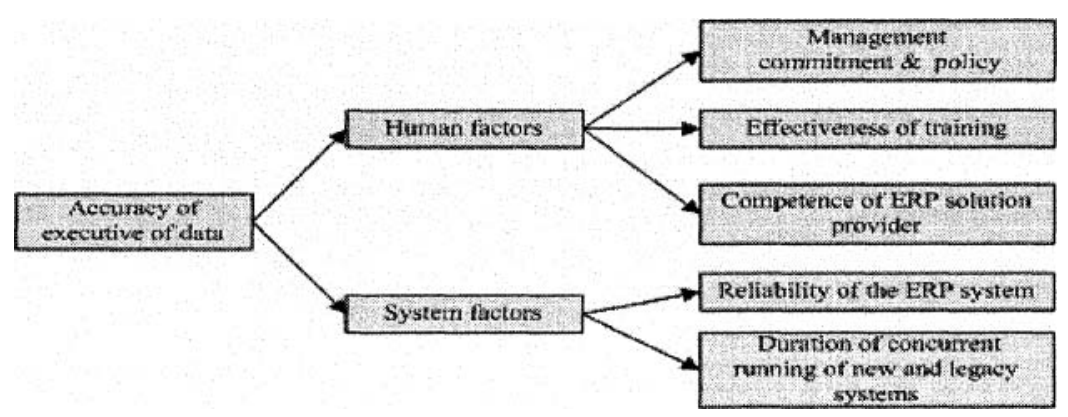

Fig. 1. Critical factors for AoD in ERP system implementation

The five influencing factors for ESI could be further elaborated by a fishbone diagram, see Fig. 2. 


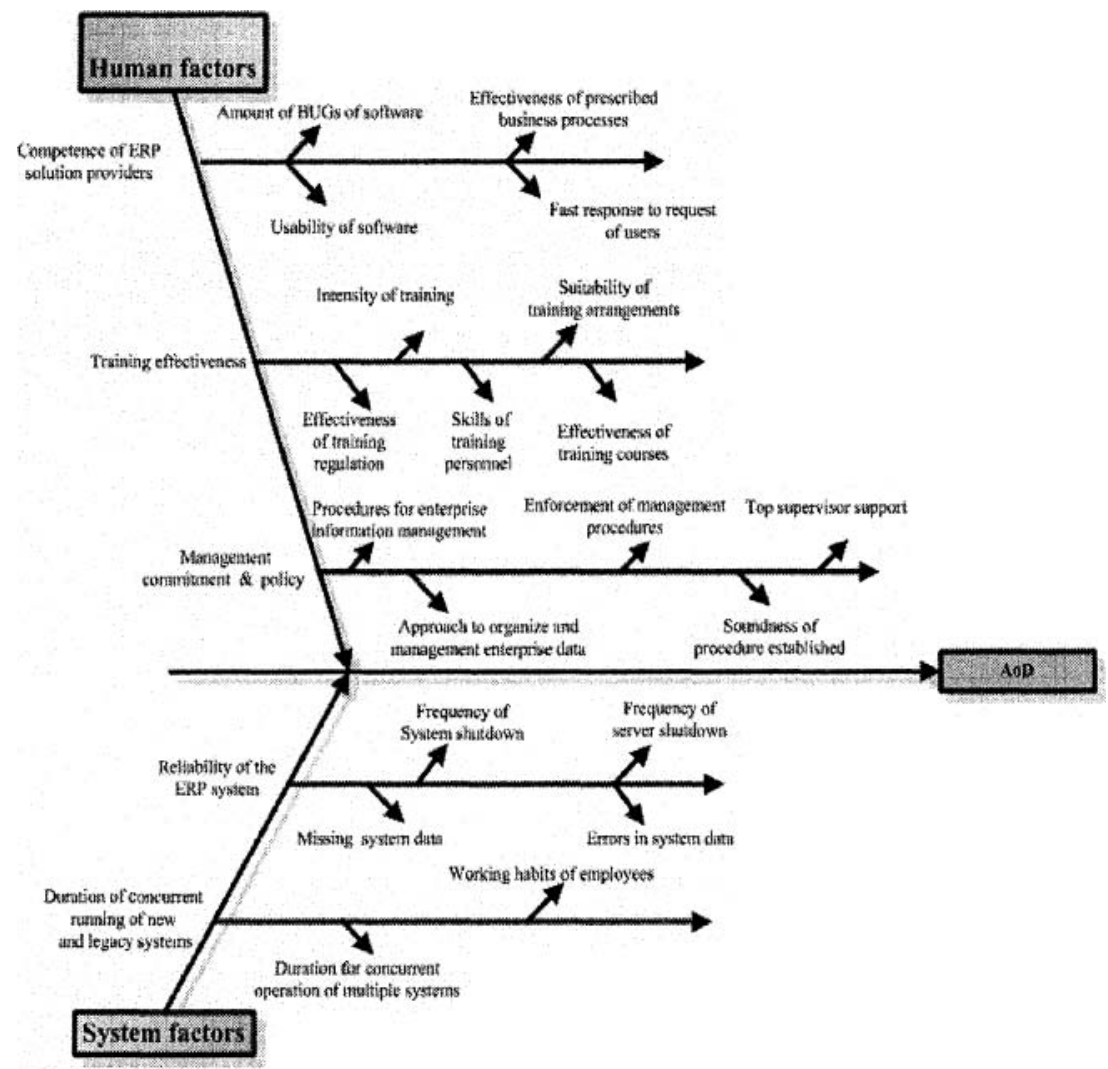

Fig. 2. Fishbone diagram of factors for $A o D$

- Management's commitment in and policy on enterprise information management include measures to establish clear and rational procedures for information management. The management will need to consider the rationality of organization planning of fundamental data, the execution level of planning and regulation, and top supervisor support for ERP implementation.

- Effectiveness of training program includes the qualification, experience and mentoring or coaching skills of the training personnel; the effectiveness of training courses, the suitability of training arrangements, the effectiveness of training regulations.

- Competence of ERP solution provider. The choice of a suitable ERP solution provider contributes critically towards the success or failure of the ERP implementation project. Its competence (or lack of it) is highlighted by the bugs contained in the software, the effectiveness of the prescribed business 
processes, the usability of software, and it response to request of users.

- The reliability of the ERP system is mainly demonstrated by the frequency of shut-down of system, the frequency of shut down of the server, missing system data and errors.

- Duration of concurrent running of new and legacy systems. After the new ERP system is operated online, usually the legacy information system could be made use of for a period at the same time which will affect data completeness and timeliness.

\subsection{The Relationship Model between Indices and the Factors relating to AoD}

Based on the analysis of the indices and the impact factors of AOD in the above sections, the relationship model between the indices and the impact factors was developed, see Table 2.

Table. 2 The Relationship Model between Indices and Impact Factors ( $V$ - Controllable; $x-$ Non-controllable)

\begin{tabular}{|c|c|c|c|c|c|c|c|}
\hline \multirow[t]{2}{*}{ Category } & \multirow[t]{2}{*}{ Factors } & \multirow[t]{2}{*}{ Sub-factors } & \multicolumn{5}{|c|}{ Indices of AoD } \\
\hline & & & Coincidence & Completeness & Timeliness & Reliability & $\begin{array}{c}\text { Logical } \\
\text { consistency }\end{array}$ \\
\hline \multirow[t]{14}{*}{ Human } & \multirow{5}{*}{$\begin{array}{l}\text { Management } \\
\text { Commitment } \\
\text { \& Policy }\end{array}$} & $\begin{array}{l}\text { Procedures for enterprise } \\
\text { information management }\end{array}$ & $\sqrt{ }$ & $\sqrt{ }$ & $\sqrt{1}$ & $\sqrt{ }$ & 1 \\
\hline & & $\begin{array}{l}\text { Enforcement of management } \\
\text { procedures }\end{array}$ & $\sqrt{ }$ & $\sqrt{1}$ & $\sqrt{ }$ & $\sqrt{ }$ & I \\
\hline & & $\begin{array}{l}\text { Approach to otganize and } \\
\text { management enterprise data }\end{array}$ & $\sqrt{ }$ & $\sqrt{1}$ & I & 7 & 7 \\
\hline & & Soundress of procedure established & $\sqrt{ }$ & 1 & 7 & 1 & 1 \\
\hline & & Top supervisor suppost & $\sqrt{1}$ & 1 & $\sqrt{1}$ & $\sqrt{ }$ & 1 \\
\hline & \multirow{5}{*}{$\begin{array}{l}\text { Training } \\
\text { effectiveness }\end{array}$} & Suitability of training arrangements & $\sqrt{ }$ & 1 & 4 & 4 & 1 \\
\hline & & Effectiveness of training regulation & $\sqrt{1}$ & $\sqrt{1}$ & i & $\sqrt{1}$ & i \\
\hline & & Intensity of training & $\sqrt{ }$ & $\sqrt{1}$ & 1 & $\frac{1}{1}$ & p \\
\hline & & Skills of training personnel & $\sqrt{ }$ & j & $\sqrt{ }$ & $\sqrt{2}$ & $\sqrt{1}$ \\
\hline & & Effectiveness of training courses & $\sqrt{ }$ & $\sqrt{ }$ & $\sqrt{ }$ & $\sqrt{1}$ & $\sqrt{ }$ \\
\hline & \multirow{4}{*}{$\begin{array}{l}\text { Competence } \\
\text { of ERP } \\
\text { Solution } \\
\text { Providers }\end{array}$} & Usability of software & $\mathrm{x}$ & 1 & 1 & $x$ & 7 \\
\hline & & Amount of bugs of software & 1 & 1 & 1 & $x$ & $x$ \\
\hline & & Fast response to request of users & 1 & 1 & 1 & $x$ & $\bar{x}$ \\
\hline & & $\begin{array}{l}\text { Effectiveness of prescribed business } \\
\text { processes }\end{array}$ & 1 & I & l & $x$ & $x$ \\
\hline \multirow[t]{6}{*}{ System } & \multirow[t]{4}{*}{ Reliability } & Frequency of system shutdown & 1 & 1 & 1 & i & $x$ \\
\hline & & Frequency of server shutdown & I & $\sqrt{1}$ & प & 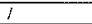 & 1 \\
\hline & & Missing system data & $T$ & 1 & 7 & $\sqrt{1}$ & 1 \\
\hline & & Errors in system data & 1 & I & 1 & 1 & 1 \\
\hline & \multirow{2}{*}{$\begin{array}{l}\text { Concurrent } \\
\text { nunning of } \\
\text { new \& legacy } \\
\text { systems }\end{array}$} & $\begin{array}{l}\text { Duration for concurrent operation } \\
\text { of multiple systems }\end{array}$ & 1 & $\sqrt{ }$ & 1 & $t$ & I \\
\hline & & Working habits of employees & $\sqrt{ }$ & $\sqrt{ }$ & 1 & 1 & $t$ \\
\hline
\end{tabular}


In Table 2, the drivers of AoD are further divided into two groups: one includes the controllable factors and the other the uncontrollable factors. The controllable factors will be further discussed in the next section.

\section{Analysis of the Controllable Factors of AoD in ERP Implementation and Related Strategies}

\subsection{The Measures for Improving AoD}

\subsubsection{Management commitment and policy}

The effectiveness of enterprise information management practices can be significantly improved with the establishment of reasonable and acceptable procedures for information management, for the enforcements of established procedures, for the support of top supervisors, and for process improvement and optimization.

\section{a. Procedures for information management for ERP}

A major requirement of AoD is the development of regulations for critical work at various points in the business processes, which can include critical control points such as warehouse-out, warehouse-entry, staff requirements, staff of record, etc.

\section{b. Enforcing the procedures}

The procedures on information management laid down by management must be effectively enforced. To achieve this, a committee has been set up which is responsible for weekly evaluations of performance in carrying out these procedures. Losses incurred due to looseness in enforcing these procedures are assessed and ways to better enforce these procedures are explored.

\section{c. The support of top supervisors}

In order to get the support of top supervisors in the ZXC company, two measures were been taken. First, during the stage of implementation of online operation, the consultants were required to provide sufficient training to top supervisors, so that they could overcome the technical and psychological barriers in using the ERP system. Second, the supervisors were encouraged to develop competence in using ERP tools such as information query via interfaces of ERP system, allowing them to make inquiries on the operational situation of the firm at any time. When the top supervisors appreciate the benefits brought about by the ERP system, they will obviously give more support to the ERP implementation. Top supervisors are thus 
encouraged to change their passive attitude towards the system and to become proactive in supporting AoD. Moreover, top supervisors will eventually influence lower level staff to also promote and support AoD activities and the ERP system.

\section{d. Process improvement and optimization}

The proposed operational procedures and processes for information processing aim at improving data coincidence and data completeness. For example, after redesigning some warehouse processes and reinforcing operational procedures, receiving activities and shipping activities will not be performed until the required documents are available.

\subsubsection{Factors relating to training and improvement measures}

According to the learning curve theory [13], training has a great impact on the effect of learning. It is also always necessary to reward effective learning during a training program. It is always constructive to motivate staff, and so prevent them from developing negative attitudes to learning when setbacks and frustrations encountered. It should be made clear that through continuous learning, they would be able to overcome the declining stage and shift to the improving stage of a learning process, as shown in the classical learning curves.

\subsubsection{Factors relating to the reliability of system and improvement measures}

The reliability of the system was improved through the following measures:

- The security control of the ERP data: hardware, human factors, catastrophes, design and maintenance.

- The equipment of the ERP system: hardware, human factors, catastrophes, pilferage and sabotage.

- The communication system: network, viruses, software, and communication transmission;

- The database management of the ERP: human factors, viruses, theft, authorization.

\subsubsection{Solution for the concurrent operation of multiple systems}

In the ZXC case study, both the new ERP system and the legacy systems (e.g. NOTES) were used concurrently for 4 months. This resulted in an adverse effect on the coincidence, the completeness, and the timeliness of the data. In order to solve the problems resulting from the simultaneous operation of new and legacy systems, the company decided to accelerate the phasing-out of the old legacy systems, and within two months the ERP system was able to run independently, producing a noticeable improvement in the AoD of system. 


\subsection{Effect Analysis of the Improvement Measures}

For the ZXC project, the related measures were implemented using the above procedures and methods of solutions, and subsequently, the AoD of system was found to have improved on all the five critical indices.

\subsubsection{The effect on coincidence}

Data coincidence for sales orders was found to have increased from $80 \%$ up to $97 \%$ (Table 2), for production tasks versus cost order it improved from $30 \%$ to $93 \%$ (Table 3), and for manual-invoicing versus system-invoicing it also improved from $77 \%$ to $96 \%$ (Table 4 ).

Table. 2 Coincidence of Sale Orders

\begin{tabular}{|l|c|c|c|}
\hline \multicolumn{1}{|c|}{ Sale order } & $\begin{array}{c}\text { Amount of } \\
\text { charge up (Time) }\end{array}$ & $\begin{array}{c}\text { Amount of error charge up } \\
\text { (Time) }\end{array}$ & Coincidence \\
\hline Before improvement & 35 & 7 & $80 \%$ \\
\hline After improvement & 32 & 1 & $97 \%$ \\
\hline
\end{tabular}

Table 3. Coincidence of Production Task vs. Cost Order

\begin{tabular}{|c|c|c|c|}
\hline Production task vs. Cost & $\begin{array}{l}\text { Amount of task } \\
\text { (Time) }\end{array}$ & Amount of error cost (Time) & Coincidence \\
\hline Before improvement & 88 & 62 & $30 \%$ \\
\hline After improvement & 76 & 5 & $93 \%$ \\
\hline
\end{tabular}

Table. 4 Coincidence of Hand Invoice vs. System Invoice

\begin{tabular}{|c|c|c|c|}
\hline Hand invoice & $\begin{array}{c}\text { Amount of } \\
\text { charge up (Time) }\end{array}$ & $\begin{array}{c}\text { Amount of crror charge up } \\
\text { (Time) }\end{array}$ & Coincidence \\
\hline Before improvement & 26 & 6 & $77 \%$ \\
\hline After improvement & 23 & 1 & $96 \%$ \\
\hline
\end{tabular}

\subsubsection{The effect on data completeness}

After the program, a noticeable improvement in data completeness was observed. Data completeness for material release per month was found to have increased from $43 \%$ to $94 \%$ (Fig. 3 ). 


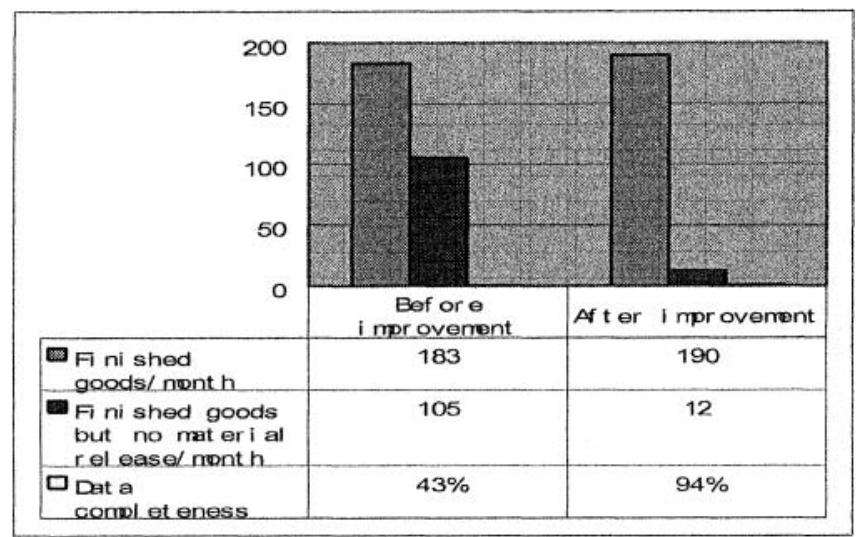

Fig. 3: Improvement of integrality of material release per month

For contracts it increased from $29 \%$ to $100 \%$, for production tasks per month it improved from $30 \%$ to $100 \%$, for purchasing orders per month it increased from $17 \%$ to $100 \%$, and for return of goods from contractors per month it improved from $23 \%$ to $78 \%$.

\subsubsection{The effect on timeliness of data}

Data timeliness of materials release on any work day has improved from around $48 \%$ to virtually $100 \%$ (Fig. 4). The timeliness of entry into the finished products warehouse on any work day has also improved form from around $15 \%$ to almost $100 \%$. By controlling the related factors, the timeliness of the data used in the ERP has considerably improved. 


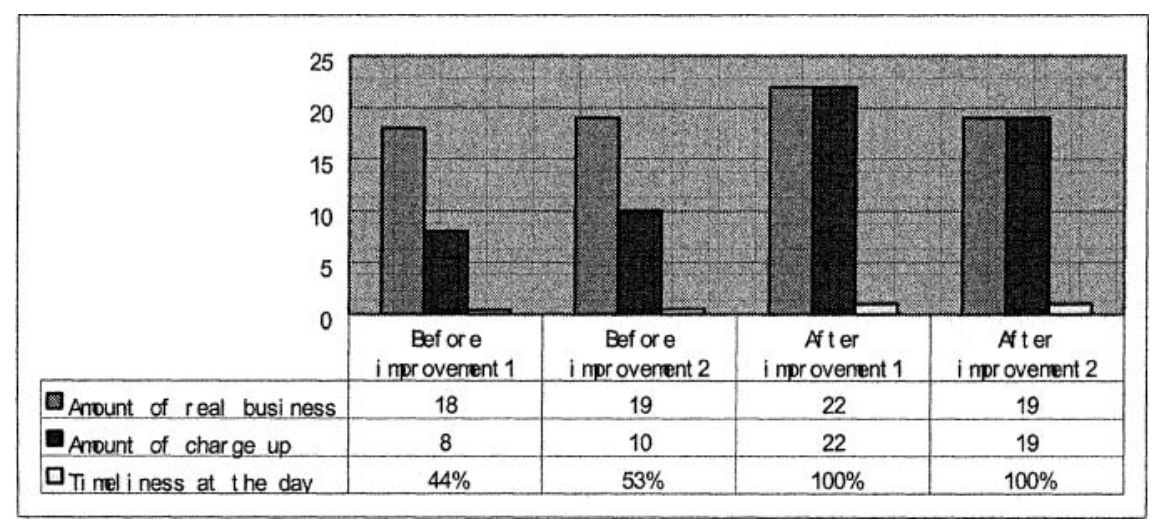

Fig.4. Improvement of timeliness of material release

\subsubsection{The effect on reliability and logical consistency}

ZXC has adopted a series of measures to enhance the reliability and logical consistency of the data. These measures include validation of user identity, authorization control, data protection, hardware investment, system update, and system training and so forth. Also, users of the system and consultants are strictly forbidden to transfer information of their accounts to outsiders. As a result, AoD has shown major improvements. The frequency of network breakdown has also fallen from around 5 times to only 1 per day. The logical data faults resulting from network breakdown have also decreased from several dozens to almost zero.

\section{Conclusion and Further Work}

We believe that AoD is the most critical issue in the successful implementation of ERP, an issue that not been addressed sufficiently by researchers. The work described in this paper has, though somewhat preliminary, has managed to contribute to and highlight the issue of $\mathrm{AoD}$. The definition of AoD has been refined through the use of the five indices of coincidence, completeness, timeliness, reliability and the logical consistency of data. These indices provide a means for assessing AoD in ERP implementation projects and are related to factors that have a clear influence AoD. Based on the proposed relationship model, approaches to the control of AoD by focusing on other controllable factors plus other process improvement initiatives have been implemented. Experience with the ZXC case suggests that the methodology developed is effective in improving AoD. It has also improved effectiveness of the enterprise information management practices, the quality of related training, and the reliability of system.

Future work is expected to focus on refining the logical relationships between the indices of $\mathrm{AOD}$ and the related factors, possibly by adopting a more quantitative approach involving Varimax correlation analysis and Logistic regressions analysis. 


\section{Acknowledgements}

The authors gratefully acknowledge funding received from the National Natural Science Foundation of China (70572038) and the foundation of Key Lab of Information Management \& Information Economics of Education Ministry, PRC, 2006-2007.

\section{References}

1. J. Motwani, D. Mirchandani, M. Madan, and A. Gunasekaran, Successful Implementation of ERP Projects: Evidence from Two Case Studies, International Journal of Production Economics 75(1-2), 83-96. (2002)

2. Y. Yusuf, A. Gunasekaran, and M.K. Abthorpe, Enterprise Information Systems Project Implementation: A Case Study of ERP in Rolls-Royce, International Journal of Production Economics 87(3), 251-266 (2004).

3. M. Al-Mashari, A. Al-Mudimigh, and M. Zairi, Enterprise Resource Planning: A Taxonomy of Critical Factors, European Journal of Operational Research 146(2), 352-364 (2003).

4. V.A. Malbert, A. Soni, and M. A. Venkataramanan, Enterprise Resource Planning: Managing the Implementation Process, European Journal of Operational Research 146(2), 302-314 (2003).

5. C. C. Sum, J. S.K. Ang, and L. N. Yeo, Contextual Elements of Critical Success Factors in MRP Implementation, Production and Inventory Management Journal 38(3), 77-83 (1997).

6. P. Bingi, M.K. Sharma, and J.K. Godla, Critical Issues Affecting an ERP Implementation, Information Systems Management 16(3), 7-14 (1999).

7. P. Mandal and A. Gunasekaran, Application of SAP R/3 in On-line Inventory Control, International Journal of Production Economics 75(1-2), 47-55 (2002).

8. K.K. Hong, and Y.G. Kim, The Critical Success Factors for ERP Implementation: An Organizational Fit Perspective, Information and Management 40(1), 25-40 (2002).

9. Z. Zhang, K.O. Lee Matthew, and P. Huang, A Framework of ERP Systems Implementation Success in China: An Empirical Study, International Journal Production Economics 98(1), 56-80 (2005).

10. L. Y. Thomas and Y. Yang, Constraint-based Wrapper Specification and Verification for Cooperative Information Systems, Information Systems 29(7), 617-636 (2004).

11. N. Robertson and T. Perera, Automated Data Collection for Simulation? Simulation Practice and Theory 9(6-8), 349-364 (2002).

12. K. K. Stephen, and R. Doron, Analysis of Tradeoff between Data Accuracy and Performance of Databases, Information System 21(8), 653-672 (1996).

13. R.B. Chase, N.J. Aquilano, and F.R. Jacobs, Production and Operations ManagementManufacturing and Service $8^{\text {th }}$ edition (China Machine Press, Beijing, 1999). 